\title{
Cytoplasmic Dynein and LIS1 Are Required for Microtubule Advance during Growth Cone Remodeling and Fast Axonal Outgrowth
}

\author{
Peter W. Grabham, ${ }^{1,3,4 \star}$ Garrett E. Seale, ${ }^{2,4 \star}$ Malika Bennecib, ${ }^{2,4}$ Daniel J. Goldberg, ${ }^{1,4}$ and Richard B. Vallee ${ }^{2,4}$ \\ Departments of ${ }^{1}$ Pharmacology and ${ }^{2}$ Pathology and Cell Biology, and Centers for ${ }^{3}$ Radiological Research and ${ }^{4}$ Neurobiology and Behavior, College of \\ Physicians and Surgeons, Columbia University, New York, New York 10032
}

\begin{abstract}
Recent evidence has implicated dynein and its regulatory factors dynactin and LIS1 in neuronal and non-neuronal cell migration. In the current study we sought to test whether effects on neuronal cell motility might reflect, in part, a role for these proteins in the growth cone. In chick sensory neurons subjected to acute laminin treatment dynein, dynactin, and LIS1 were mobilized strikingly and rapidly to the leading edge of the growth cone, where they were seen to be associated with microtubules converging into the laminin-induced axonal outgrowths. To interfere acutely with LIS1 and dynein function and to minimize secondary phenotypic effects, we injected antibodies to these proteins just before axon initiation. Antibody to both proteins produced an almost complete block of laminin-induced growth cone remodeling and the underlying reorganization of microtubules. Penetration of microtubules into the peripheral zone of differentiating axonal growth cones was decreased dramatically by antibody injection, as judged by live analysis of enhanced green fluorescent proteintubulin and the microtubule tip-associated EB3 (end-binding protein 3). Dynein and LIS1 inhibition had no detectable effect on microtubule assembly but reduced the ability of microtubules to resist retrograde actin flow. In hippocampal neurons dynein, dynactin, and LIS1 were enriched in axonal growth cones at stage 3 , and both growth cone organization and axon elongation were altered by LIS1 RNA interference. Together, our data indicate that dynein and LIS1 play a surprisingly prominent role in microtubule advance during growth cone remodeling associated with axonogenesis. These data may explain, in part, the role of these proteins in brain developmental disease and support an important role in diverse aspects of neuronal differentiation and nervous system development.
\end{abstract}

Key words: growth cone; dynein; LIS1; microtubule; axon; outgrowth

\section{Introduction}

Lissencephaly is a severe brain malformation characterized by abnormal migration of neural progenitor cells from the ventricular zone to the developing cortical plate. Mutations in the human LIS1 gene cause type I lissencephaly (Reiner et al., 1993; Hattori et al., 1994). LIS1 has been identified as a noncatalytic subunit of platelet-activating factor acetylhydrolase $1 \mathrm{~b}$ (Hattori et al., 1994). However, mice null for the catalytic subunits of this enzyme showed no defects in brain development (Koizumi et al., 2003; Yan et al., 2003). LIS1 also interacts with cytoplasmic dynein and its accessory complex dynactin (Faulkner et al., 2000; Sasaki et al., 2000; Smith et al., 2000; Tai et al., 2002). Through interaction with these proteins, LIS1 plays an important role in microtubule-related cellular functions such as nuclear migration

Received May 8, 2006; accepted April 17, 2007.

This work was supported by grants from National Institutes of Health (NS41728 to D.J.G. and GM47434 and HD40182 to R.B.V.) and the National Science Foundation (IOB-0544710 to D.J.G.). We thank Dr. R. Robinson for the use of the nucleofector equipment and Dr. C. Mason for help with hippocampal cultures. We also thank Dr. D. Meyer for Arp-1 antibody and Dr. N. Galjart for GFP-EB3 constructs.

*P.W.G. and G.E.S. contributed equally to this study.

Correspondence should be addressed to Dr. Richard B. Vallee, Department of Pathology and Cell Biology, College of Physicians and Surgeons, Columbia University, Physicians and Surgeons 15-409, 630 West 168th Street, New York, NY 10032. E-mail: rv2025@columbia.edu.

DOI:10.1523/JNEUROSCI.1135-07.2007

Copyright $\odot 2007$ Society for Neuroscience $\quad$ 0270-6474/07/275823-12\$15.00/0
(Hirotsune et al., 1998; Tanaka et al., 2004; Xiang and Fischer, 2004; Tsai et al., 2005), mitotic-spindle orientation, and chromosome capture (Faulkner et al., 2000). LIS1 and cytoplasmic dynein also have been implicated in directed cell migration. Inhibition of dynein or dynactin interfered with the reorientation of the centrosome toward the leading cell edge in wounded fibroblast monolayers (Etienne-Manneville and Hall, 2001; Palazzo et al., 2001). Inhibition of these proteins or LIS1 also interfered with forward migration of fibroblasts (Dujardin et al., 2003). LIS1 ${ }^{+/-}$ fibroblasts isolated from primary brain cultures also were reported to show a decrease in overall motility rate (Kholmanskikh et al., 2003). Of considerable interest, cytoplasmic dynein, its regulatory complex dynactin, and LIS1 all accumulated at the leading edge of active ruffling lamellipodia, consistent with a role in pulling on microtubules from this site (Dujardin et al., 2003)

The current study was initiated to determine whether dynein, dynactin, and LIS1 play a related role in neuronal cells. Previous studies have identified defects in axonal pathfinding in Drosophila cytoplasmic dynein light chain and dynactin Glued mutants (Phillis et al., 1996; Allen et al., 1999). We also recently observed severe defects in axonal elongation by live cell imaging of neocortical neural progenitor cells subjected to LIS1 RNA interference (RNAi) (Tsai et al., 2005). In the current study we were particularly interested in behavior associated with the neuronal growth 
cone, the motility of which is based on principles common to those underlying lamellipodial behavior, but with the added necessity to leave behind an elongating axon.

Rapid reorganization of the growth cone and its microtubuleand actin-rich domains is associated with axonogenesis. These changes occur spontaneously in hippocampal neurons during polarization in vitro. This transition can be controlled in other vertebrate neurons by acute application of laminin. Laminin is an extracellular matrix glycoprotein widely studied for its ability to stimulate selectively the differentiation and rapid growth of axons. Rapid growth of morphologically and biochemically differentiated axons results from exposure to laminin precoated on the substrate (Lein and Higgins, 1989; Lein et al., 1992) or added acutely to the culture medium (Chamak and Prochiantz, 1989; Lein and Higgins, 1989; Tang and Goldberg, 2000). In the latter case, laminin still appears to function in its normal substrate role (Grabham et al., 2003). Furthermore, this response is specific to laminin, because fibronectin does not stimulate the growth of rapidly advancing axons (Grabham et al., 2003). The transformation of a slowly growing undifferentiated neurite into a rapidly growing axon begins within minutes of exposure to laminin and involves a major reorganization of the cytoskeleton of the growth cone (Rivas et al., 1992; Esch et al., 1999; Tang and Goldberg, 2000; Grabham et al., 2003). The growth cone has two major cytoplasmic domains: a peripheral actin-rich lamellipodial and filopodial zone and a central microtubule-rich zone in which vesicular organelles are concentrated. Laminin addition results in the extension of microtubules into the peripheral zone (P-zone), where they become bundled and appear to interact with the leading growth cone edge (Rivas et al., 1992). The use of this model allowed us to monitor the localization of dynein during these microtubule changes.

We report that dynein, dynactin, and LIS1 exhibit clear changes in distribution within the growth cones of laminintreated chick dorsal root ganglia (DRG) and spontaneously polarizing rat hippocampal neurons. Interference with dynein and LIS1 produced surprisingly pronounced inhibition of growth cone remodeling and neurite outgrowth in the chick neurons, a result supported by LIS1 RNAi in hippocampal neurons. Microtubule reorganization in each case also was severely compromised, an effect we can attribute not to altered microtubule assembly or transport but, instead, to the inability of microtubules to resist rearward cytoplasmic forces. These results identify a novel and prominent role for dynein and LIS1 in growth cone behavior, which has important implications for understanding axonal growth, neuronal migration, and brain developmental disease.

\section{Materials and Methods}

Neuronal culture. DRG neurons were dissected from embryonic day 10-13 (E10-E13) chick embryos, washed in Hank's medium (Sigma, St. Louis, MO), and followed by $0.25 \%$ trypsin treatment (Sigma) for $15 \mathrm{~min}$ at $37^{\circ} \mathrm{C}$. Using a fire-polished Pasteur pipette, we triturated and plated cells onto dishes coated with $0.1 \mathrm{mg} / \mathrm{ml}$ each of poly-D-lysine and polyornithine. Cells were grown overnight in L-15 medium (Sigma) supplemented with $8 \%$ heat-inactivated horse serum (Invitrogen, San Diego, CA), $4 \%$ fetal bovine serum (Invitrogen), $0.2 \mathrm{mg} / \mathrm{ml}$ glutamine (Sigma), and $50 \mathrm{ng} / \mathrm{ml} \mathrm{NGF}$ (Alomone Labs, Jerusalem, Israel). The next day the cells were washed several times with L-15 serum-free medium containing $1 \%$ BSA (Sigma), $0.2 \mathrm{mg} / \mathrm{ml}$ glutamine, $10 \mu \mathrm{g} / \mathrm{ml}$ transferrin, $5 \mu \mathrm{g} / \mathrm{ml}$ insulin, $5 \mathrm{ng} / \mathrm{ml}$ sodium selenite, $1 \mathrm{~mm}$ sodium pyruvate, and $50 \mathrm{ng} / \mathrm{ml}$ NGF. Laminin (Roche Bioscience, Palo Alto, CA) treatment was performed at a final concentration of $20 \mu \mathrm{g} / \mathrm{ml}$.

Embryonic hippocampal neuron cultures were prepared from E18-
E19 rat embryos according to Institutional Animal Care and Use Committee regulations. Briefly, hippocampi were dissected in HBSS containing $10 \mathrm{~mm}$ HEPES (Sigma) and incubated for $15 \mathrm{~min}$ at $37^{\circ} \mathrm{C}$ with $0.25 \%$ trypsin (Sigma). Hippocampi then were triturated in the plating medium DMEM containing 10\% FBS, $0.5 \mathrm{~mm}$ L-glutamine, and $1 \mathrm{~mm}$ sodium pyruvate (Invitrogen). After trituration the cells were plated at a density of 160 cells $/ \mathrm{mm}^{2}$ in the center wells of $50 \mathrm{~mm}$ MatTek (Ashland, MA) imaging dishes that were precoated overnight with $0.5 \mathrm{mg} / \mathrm{ml}$ poly-Dlysine in borate buffer and were incubated with plating medium at $37^{\circ} \mathrm{C}$ during the dissection. Once the cells had adhered to the substrate after $2 \mathrm{~h}$ in the plating medium, the medium was removed completely and replaced with Neurobasal medium (Invitrogen) containing B-27 supplement (Invitrogen) and $0.5 \mathrm{~mm}$ L-glutamine. Cultures were grown for 1-5 DIV before fixation.

Immunological methods. Antibodies against the $74 \mathrm{kDa}$ dynein intermediate chain (IC) (Chemicon, Temecula, CA), tubulin (Sigma), and actin-related protein 1 (Arp1) (provided by D. Meyer, University of California at Los Angeles, Los Angeles, CA) were used for immunofluorescence microscopy of cells fixed with cold methanol for $5 \mathrm{~min}$ at $-20^{\circ} \mathrm{C}$. For staining with $\mathrm{p} 150^{\text {Glued }}$ monoclonal antibody (Transduction Laboratories, Lexington, KY) or LIS1 polyclonal antibody (Santa Cruz Biotechnology, Santa Cruz, CA) the cells were fixed in cacodylate buffer [containing the following (in $\mathrm{mm}$ ): 134 sodium cacodylate, $10 \mathrm{MgCl}_{2}, 5$ $\mathrm{CaCl}_{2}$, pH 7.4] containing $0.25 \%$ glutaraldehyde for $5 \mathrm{~min}$ at $37^{\circ} \mathrm{C}$, followed by one rinse in PBS before permeabilization with $0.5 \%$ Triton X-100 in PBS (Lewis and Bridgman, 1996). Then the preparation was blocked at $37^{\circ} \mathrm{C}$ for $30 \mathrm{~min}$ in PBS containing $10 \%$ BSA before being incubated with the corresponding primary antibody overnight at $4^{\circ} \mathrm{C}$ in PBS containing $0.1 \%$ BSA and $0.05 \%$ sodium azide. Secondary antibody staining was performed for $1 \mathrm{~h}$ at $37^{\circ} \mathrm{C}$ with Alexa Fluor-conjugated anti-IgG antibodies (Invitrogen) at a working dilution of 1:1000. After a final wash in PBS the preparations were mounted with $20 \mathrm{mg} / \mathrm{ml}$ propyl gallate in $90 \%$ glycerol/10\%PBS. Images were collected with a Nikon (Tokyo, Japan) or a Leica (Nussloch, Germany) inverted epifluorescence microscope or, where noted, a Nikon Eclipse TE2000- $\mu$ microscope equipped with a Turnkey total internal reflection fluorescence (TIRF) module. Images were processed and analyzed with MetaMorph (Universal Imaging, West Chester, PA) and Photoshop (Adobe Systems, Mountain View, CA) software.

The ratio of dynein and LIS1 relative to total protein was determined by using the ratio image function in MetaMorph. Dynein IC or LIS1 images were selected as the numerator and 5-(4,6-dichloro-s-triazin-2ylamino) fluorescein (DTAF) images were selected as the denominator. The minimum ratio value was set to 0 , and the maximum ratio value was set to 5 . The resulting eight-bit images were pseudo-colored to produce images with a scale of $0-255$ corresponding to black/dark blue as the lowest and red/white as the highest increase over DTAF staining.

Immunoblotting was performed against total embryonic chick brain cytosolic extract or embryonic rat hippocampal culture lysates (1 DIV) with the same antibodies that were used for immunocytochemistry.

Transfection. Cultures of DRG neurons were transfected by the use of a nucleofection apparatus (Amaxa, Gaithersburg, MD). The $1.7 \times 10^{6}$ cells were resuspended into $100 \mu \mathrm{l}$ of transfection solution (DRG Nucleofection kit, Amaxa) before being electroporated with $5 \mu \mathrm{g}$ of enhanced green fluorescent protein-tubulin (EGFP-tubulin) (Clontech, Palo Alto, CA) or GFP-end-binding protein 3 (GFP-EB3), using the G-13 program. Cells were cultured overnight in serum-containing medium and then switched to serum-free defined medium before injection. In the case of the hippocampal cultures the same procedure and parameters as above were used for electroporation of LIS1 RNAi and scrambled control constructs, except that the O-03 program on the Amaxa nucleofector machine was used instead.

Live cell imaging and microinjection. Primary neuronal cultures were placed on a motorized stage of a Nikon TE 200 inverted microscope heated to $37^{\circ} \mathrm{C}$. Oxyrase $(1: 100)$ was added to the medium, and $1 \mathrm{ml}$ of dimethylpolysiloxane was layered on top to prevent cooling, evaporation, and excess oxygenation. Cells were observed with a $40 \times$ neofluor/ 1.3 numerical aperture (NA) objective, and images were captured by using a cooled CCD camera (Princeton Instruments, Trenton, NJ). Dif- 
tubulin
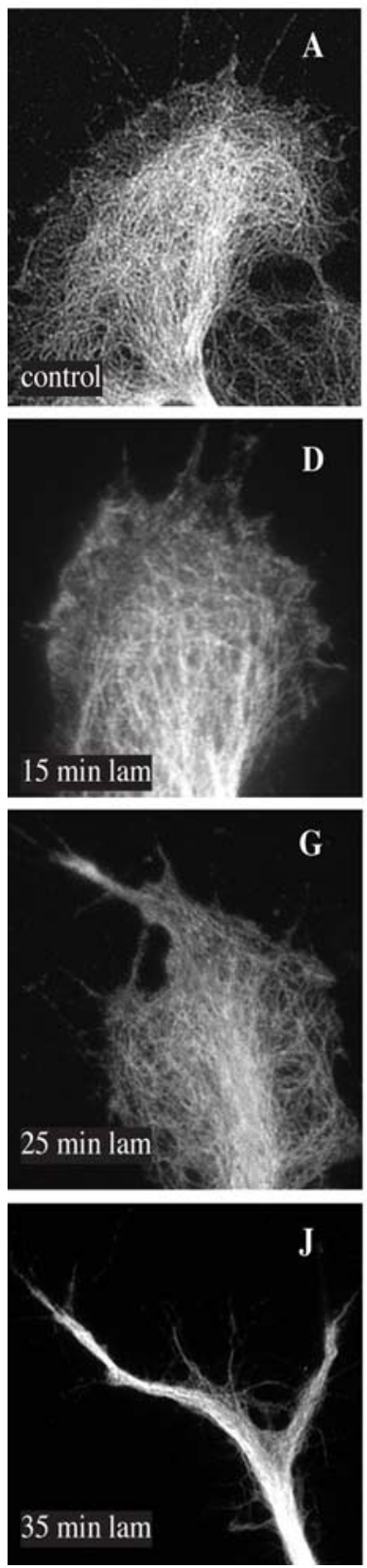

dynein
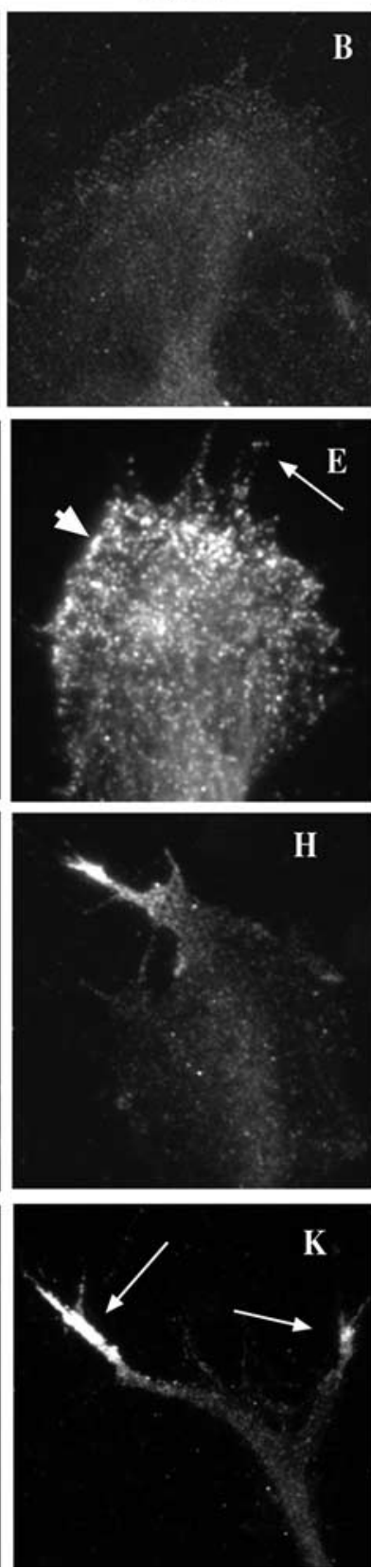

merge
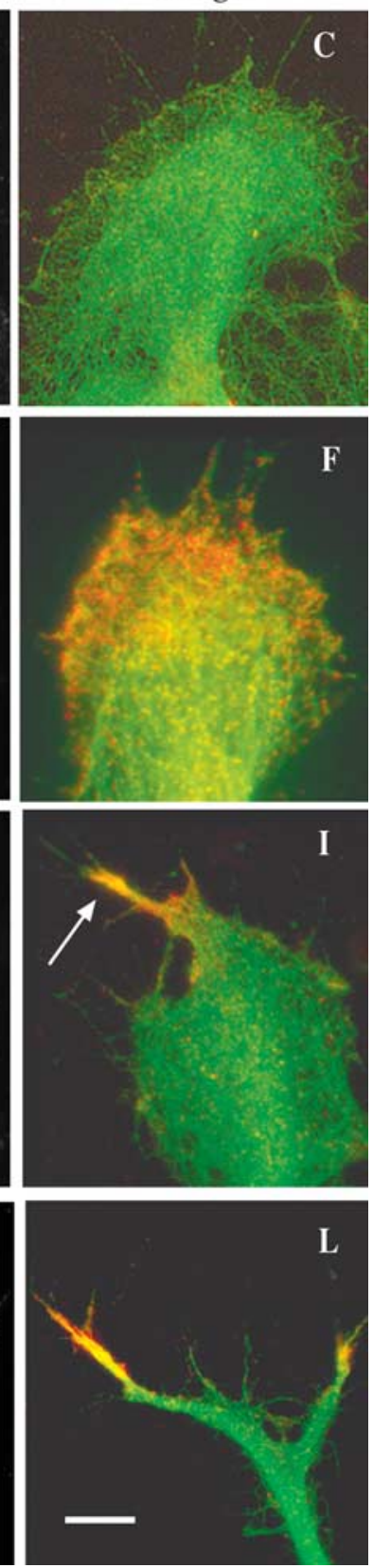

Figure 1. Effects of laminin on cytoplasmic dynein distribution within growth cones. DRG neurons from E10 -E13 chick embryos were grown on polyamine-coated coverslips and then exposed to laminin. Cells were fixed in methanol and analyzed by immunofluorescence microscopy with the use of antibodies against tubulin and dynein IC. $A-C$, Before laminin treatment, weak, diffuse dynein staining is observed throughout the growth cone. $\boldsymbol{D}-\boldsymbol{F}$, After $15 \mathrm{~min}$ in laminin dynein accumulates toward the leading edge of the growth cone (arrowhead) and within filopodia (arrow). G-I, After $25 \mathrm{~min}$ in laminin dynein is enriched in nascent processes in association with bundled microtubules (arrow). $J-L$, After $35 \mathrm{~min}$ in laminin dynein is associated with the tips of rapidly extending outgrowths (arrows). $C, F, I$, and $L$ represent merged images of tubulin (green) and dynein (red). Scale bar: (in L) $A-L, 10 \mu \mathrm{m}$.

ferential interference contrast (DIC) optics were used to record stage coordinates of suitable growth cones. Monoclonal anti-dynein IC IgGs (Chemicon), control mouse IgG (Sigma), and an IgG fraction (Pierce, Rockford, IL) prepared from a rabbit polyclonal antibody raised against the N-terminal 21 aa of primate LIS1 (Faulkner et al., 2000) were each concentrated to $\sim 15 \mathrm{mg} / \mathrm{ml}$ and resuspended into intracellular medium buffer (Invitrogen). Alexa-dextran 595 (0.125 M; Invitrogen) was included as an injection marker. Material was pressure-injected into the cytoplasm of the cell body by using backloaded femto II tips (Brinkmann Instruments, Westbury, NY) attached to a hydraulic manipulator as pre- viously described (Grabham et al., 2003). Neurite length was generally $<50 \mu \mathrm{m}$, and the Alexa-dextran reached the growth cones in $<4$ min. Laminin was added at least $30 \mathrm{~min}$ after injection. Cell coordinates were recorded, and the cells were located automatically by a computer-driven stage (MetaMorph) for timelapse imaging. Only cells expressing a moderate amount of GFP-EB3 showed comet tails, and these were chosen for recordings. Time-lapse images ( $2 \mathrm{~s}$ intervals) of eight growth cones each for control IgG and $\alpha 74.1$ IgG were acquired for periods of $1 \mathrm{~min}$ via a $100 \times / 1.4 \mathrm{NA}$ objective. Comet tail pauses were defined as periods of immobilization lasting at least $2 \mathrm{~s}$ (1 frame). History maps of superimposed images were created in AutoDeblur (AutoQuant software, Media Cybernetics, Silver Spring, MD). Comparison of comet tail rates for significance of differences was done by using ANOVA and Bonferroni's modified $t$ test for multiple comparisons.

Hippocampal neuron staging and axonal length measurements. After fixation and staining of 1-5 DIV hippocampal neurons the images were captured for analysis of axonal length measurements and microtubule organization in axonal growth cones and shafts. The following conditions were used to stage pyramidal neurons and measure axon lengths accurately. (1) Only pyramidal neurons with three or more processes (each $>5 \mu \mathrm{m}$ in length) were analyzed. (2) An axon was defined as a process at least $40 \mu \mathrm{m}$ long and at least $30 \mu \mathrm{m}$ longer than the other processes of that neuron. Neurons with a process that satisfied this condition were categorized as stage 3 neurons, whereas those neurons with processes that did not satisfy this condition were categorized as stage 2 neurons. With the use of these parameters hippocampal pyramidal neurons expressing LIS1 RNAi and scrambled control constructs were staged, and the lengths of their axons and minor neurites were measured.

\section{Results \\ Localization of dynein within the growth cone}

To monitor the distribution and redistribution of dynein in growth cones during axon formation, we exposed DRG neurons dissected from E10-E13 chick embryos and grown on polyamines to laminin for a series of time periods, fixed them, and subsequently labeled them with a monoclonal antibody against dynein IC and a polyclonal antibody against tubulin.

This treatment results in an average of approximately two new axons emerging from each growth cone (Grabham et al., 2003). Before laminin treatment only a moderate level of diffuse dynein staining was seen in the central region, with little detectable staining in the peripheral region (Fig. $1 B$ ). After $15 \mathrm{~min}$ in laminin, dispersed punctate dynein staining appeared at the leading edge of the growth cone at sites to which microtubules had advanced (Fig. $1 E$, arrowhead). Some dynein spots also were associated with filopodia (Fig. $1 E$, arrow). After $25 \mathrm{~min}$ in laminin the microtubules had begun to extend as bun- 
dles into emerging axons (Fig. $1 G-I$ ). At this stage bright dynein staining could be observed to be associated with the bundled microtubules in the nascent processes (Fig. 1I, arrow). After more extended laminin exposure, the processes elongated (Fig. $1 J-L$ ). Dynein staining was weak along the length of these processes but strongly concentrated near the distal ends (Fig. $1 \mathrm{~K}$, arrows). Of the new outgrowths $83 \%(n=71)$ were observed to stain brightly at their tips with anti-dynein antibody.

As we had observed previously in migrating fibroblasts (Dujardin et al., 2003), dynein staining was not restricted to microtubules but appeared to be associated more broadly with the leading growth cone edge at sites of axon formation. Furthermore, dynein became enriched toward the leading edge even before the appearance of new processes was evident (Figs. $1 D-F, 2 A$ ). This effect was judged to reflect true enrichment of dynein, because it was observed even in comparison to a general protein stain, DTAF (Fig. 2B). As an additional test for dynein enrichment we used TIRF microscopy, which illuminates the bottom 100-200 nm of the cell. As previously observed in lamellipodia (Dujardin et al., 2003), we still saw dynein staining to be concentrated toward the leading edge (Fig. 2D, G). The pattern of staining was even more clearly punctate than in the epifluorescence images. In some cases puncta appeared to be aligned along microtubules or associated with their ends.

\section{Localization of the dynein regulatory proteins dynactin and LIS1 within the growth cone}

LIS1 and subunits of the dynactin complex Arp 1 and $150^{\text {Glued }}$ were found to colocalize with cytoplasmic dynein within active lamellipodia, and LIS1 and dynactin were found to participate in directed cell movement in wounded fibroblast monolayers (Dujardin et al., 2003). Therefore, we also looked at the distribution of these proteins within the growth cone. Before laminin treatment LIS1 and the Arp1 and p150 Glued subunits of the dynactin complex weakly stained the growth cone (data not shown). After laminin treatment LIS1 clearly was enriched at sites within the growth cone to which microtubules had converged, as we had observed for cytoplasmic dynein (Fig. 3A). Arp1 and p $150^{\text {Glued }}$ also were enriched in emerging laminin-induced outgrowths (Fig. 3A). Double labeling for p150 ${ }^{\text {Glued }}$ and LIS1 (Fig. $3 B$ ) and for dynein IC and LIS1 (data not shown) revealed colocalization of dynein, dynactin, and LIS1 at common sites within the same growth cones. Staining for p $150^{\text {Glued }}$ was spread more extensively along microtubules within the growth cone because of the association of dynactin with growing microtubule ends (Vaughan et al., 1999).
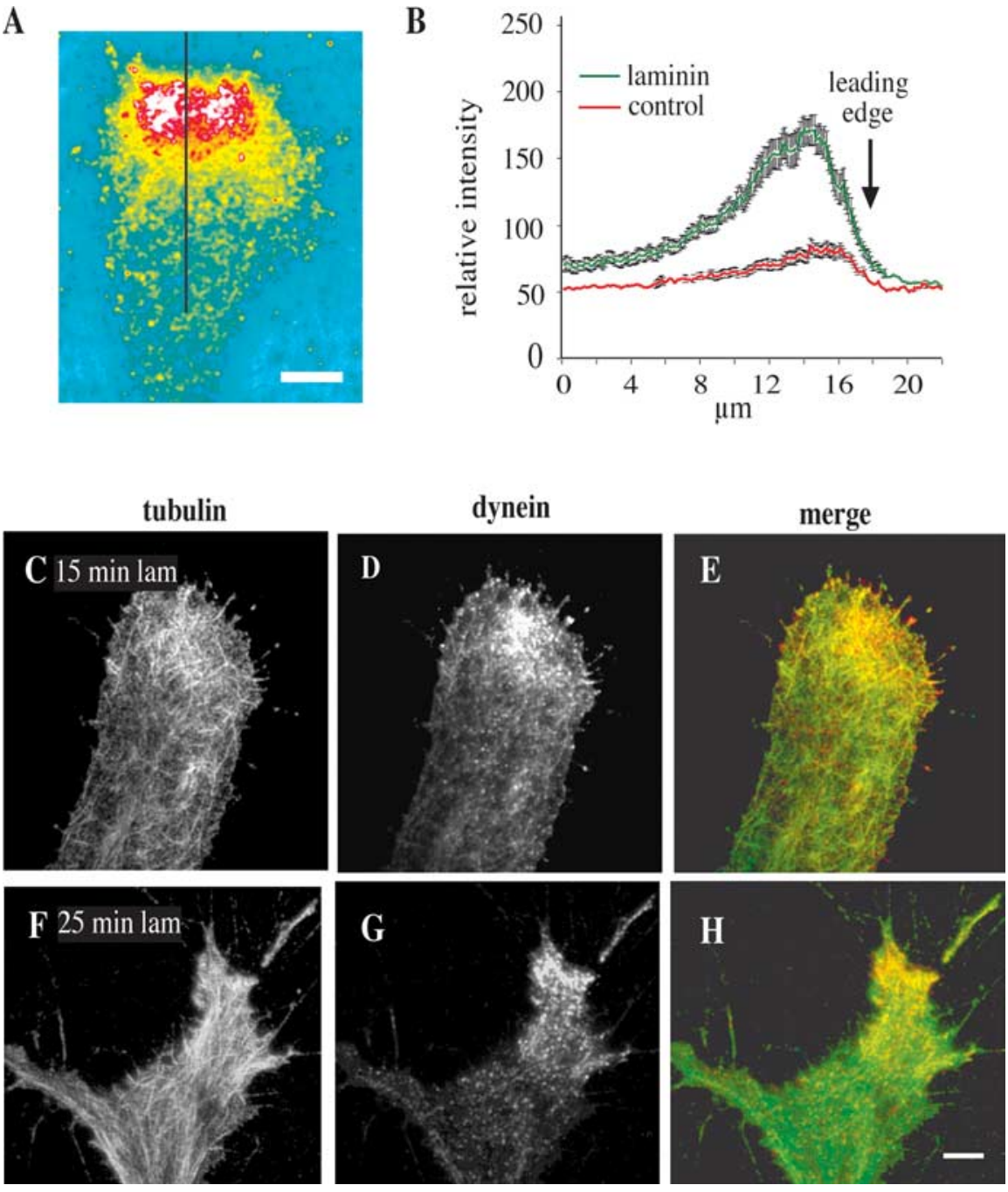

Figure 2. Enrichment of dynein within DRG growth cones. $\boldsymbol{A}, \boldsymbol{B}$, Quantitation of dynein IC immunofluorescence relative to total edge (black line in $\boldsymbol{A}$ ) (see Materials and Methods). Scale bar, $5 \mu \mathrm{m}$. Relative fluorescent intensity is greatest close to the leading (B). Error bars represent the SEM. $\boldsymbol{C}-\boldsymbol{H}$, TIRF microscopy was performed on chick DRG neurons treated with laminin and stained with 列 bundled microtubules. Dynein staining generally was observed to be punctate in these images. Scale bar: (in $\boldsymbol{H}) \boldsymbol{C}-\boldsymbol{H}, 10 \mu \mathrm{m}$.

To test whether dynein and LIS1 associate with developing axonal growth cones more generally, we examined their distribution relative to DTAF in chick DRG neurons plated and grown continuously on laminin, rather than immediately after acute laminin addition (Fig. 4A), and in rat hippocampal neurons (Fig. $4 B)$. Staining for dynein in the chick neurons was comparable to that observed after $1 \mathrm{~h}$ or more of acute laminin treatment. In stage 2 hippocampal neurons LIS1 generally was observed to be weak and diffuse, although staining at a single neurite tip could be observed in some neurons at this stage (Fig. 4B) (supplemental data 3, available at www.jneurosci.org as supplemental material). By stage 3 this pattern was observed consistently, with $85 \%$ of morphologically identifiable axons having a pronounced enrichment of LIS1 within their growth cones, whereas growth cones of undifferentiated neurites in the same cells generally did not have marked concentrations of LIS1. Comparable distributions of dynein IC and the dynactin subunit p $150^{\text {Glued }}$ in stage 2 versus stage 3 growth cones also were observed (data not shown). 

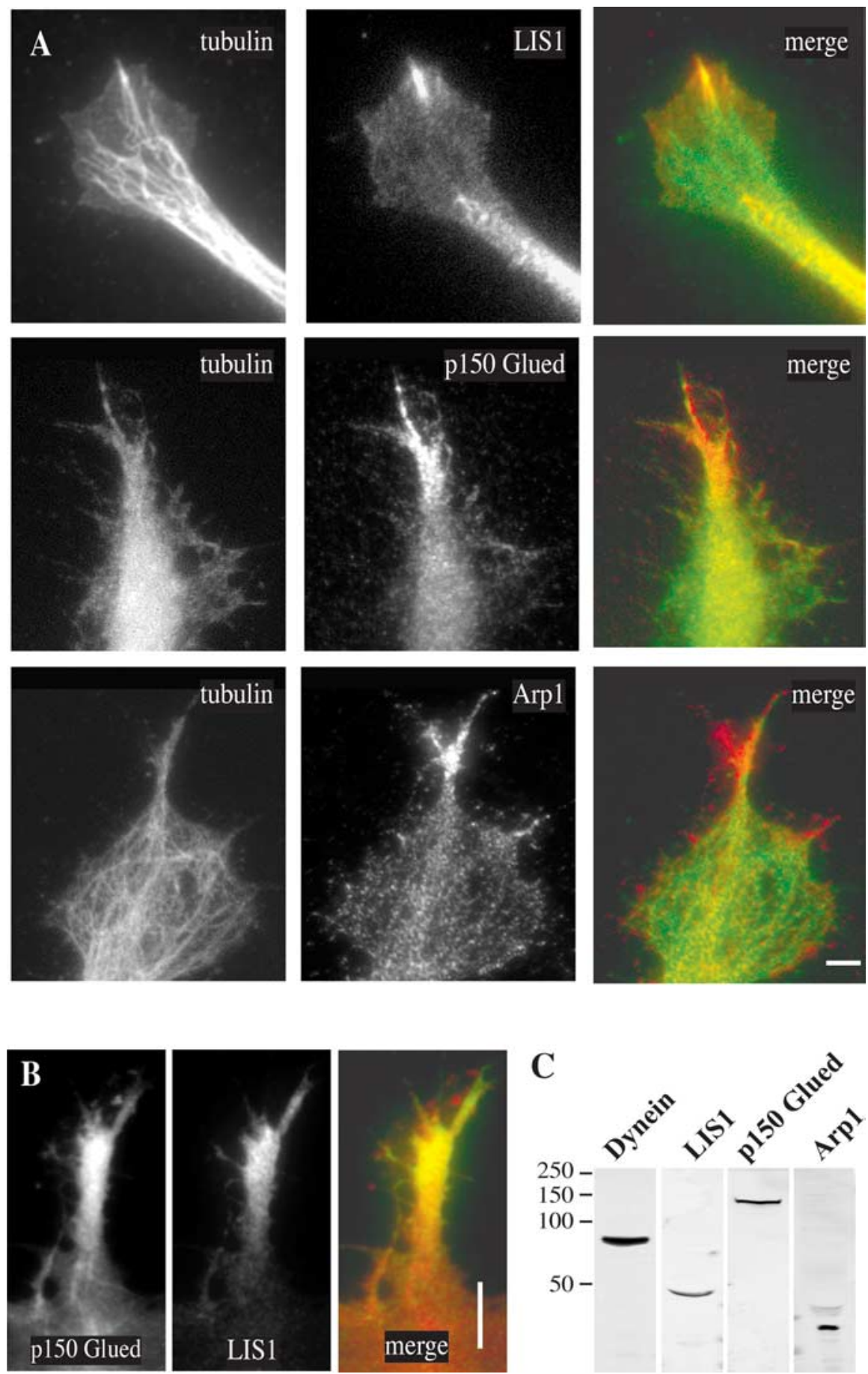

Figure 3. A, Localization of LIS1 and dynactin to sites of emerging axons. Chick DRG neurons were exposed to laminin for 25 min and then stained with anti-tubulin, anti-LIS1, anti-p150 Glued, and anti-Arp1 antibodies. All three of the latter antigens were enriched at sites of nascent axon outgrowth to which dynein was localized and microtubules had converged. Scale bar, $10 \mu \mathrm{m} . \boldsymbol{B}$, Colocalization of $150^{\text {Glued }}$ and LIS1 in outgrowths 30 min after laminin. Scale bar, $5 \mu \mathrm{m}$. C, Immunoblot of chick brain extract with the antibodies used for immunofluorescence microscopy shows that these antibodies react with chick neural tissue.

\section{Inhibition of dynein and LIS1}

Together, these data suggested a potential role for dynein, dynactin, and LIS1 in growth cone remodeling associated with the initiation of rapid axonal growth. To test this hypothesis, we performed LIS1 RNAi in hippocampal neurons, using vectorbased RNAi with reagents described previously (Tsai et al., 2005), which we had found to arrest neuronal migration in live brain slices. We had found LIS1 levels to be reduced in cultured cell lines as judged by immunoblotting. LIS1 immunofluorescence also was reduced in situ in the transfected brain neurons and in the cultured hippocampal neurons used in the current study (supplemental data 4, available at www.jneurosci.org as supplemental material). We found LIS1 knockdown to result in a moderate delay in the onset of polarization in the hippocampal neurons (data not shown) and in a decrease in axon length (Fig. 4D). The distal axon was abnormally wide with spread microtubules (Fig. 4C). Lamellipodial protrusions along the margins of this domain were also observed.

Neither RNAi nor dominant-negative LIS1, dynactin, and dynein cDNAs (Echeverri et al., 1996; Faulkner et al., 2000; Tai et al., 2002; D. Varma and R. Vallee, unpublished results) were suitable for the chick DRG neurons, which remained responsive to acute addition of laminin for only $\sim 18 \mathrm{~h}$. Instead, we injected the cells with dynein and LIS1 function-blocking antibodies. The antidynein antibody reacts with the N-terminal 63 aa of the IC polypeptide (Susalka et al., 2002; K. Vaughan and R. Vallee, unpublished observations) and, like other antibodies that react within this region, is thought to block the interaction of the IC with the p150 Glued subunit of the dynactin complex (Steffen et al., 1997). This antibody has been used repeatedly at similar concentrations to interfere with dynein function (Faulkner et al., 2000; Palazzo et al., 2001; Burakov et al., 2003; Dujardin et al., 2003). The anti-LIS1 antibody causes clear interference with mitotic chromosome alignment, marked delays in mitosis, and chromosome loss (Faulkner et al., 2000). The antibody was generated against the first $21 \mathrm{~N}$-terminal amino acids of LIS1, part of the LIS1homology domain (Kim et al., 2004), which is now known to be involved in selfassociation (Tai et al., 2002; Kim et al., 2004; Tarricone et al., 2004). Antibodies were injected into the cell bodies of the DRG neurons. A marker dye reached the growth cone within $5 \mathrm{~min}$, and phenotypic effects were observed within less than one-half hour.

Inhibition of dynein by antibody microinjection greatly reduced the emergence of new axons in response to laminin (Figs. 5, 6). Overall, $62 \%$ of chick DRG neurons microinjected with a control mouse IgG produced one or more new thin processes, a behavior seen in only $15 \%$ of dynein antibody-injected neurons. In these latter cases the average number of new axons per growth cone also was reduced markedly (Fig. 5B).

To understand the basis for this effect, we monitored the morphology and advance of the growth cone and neurite(s) by time 

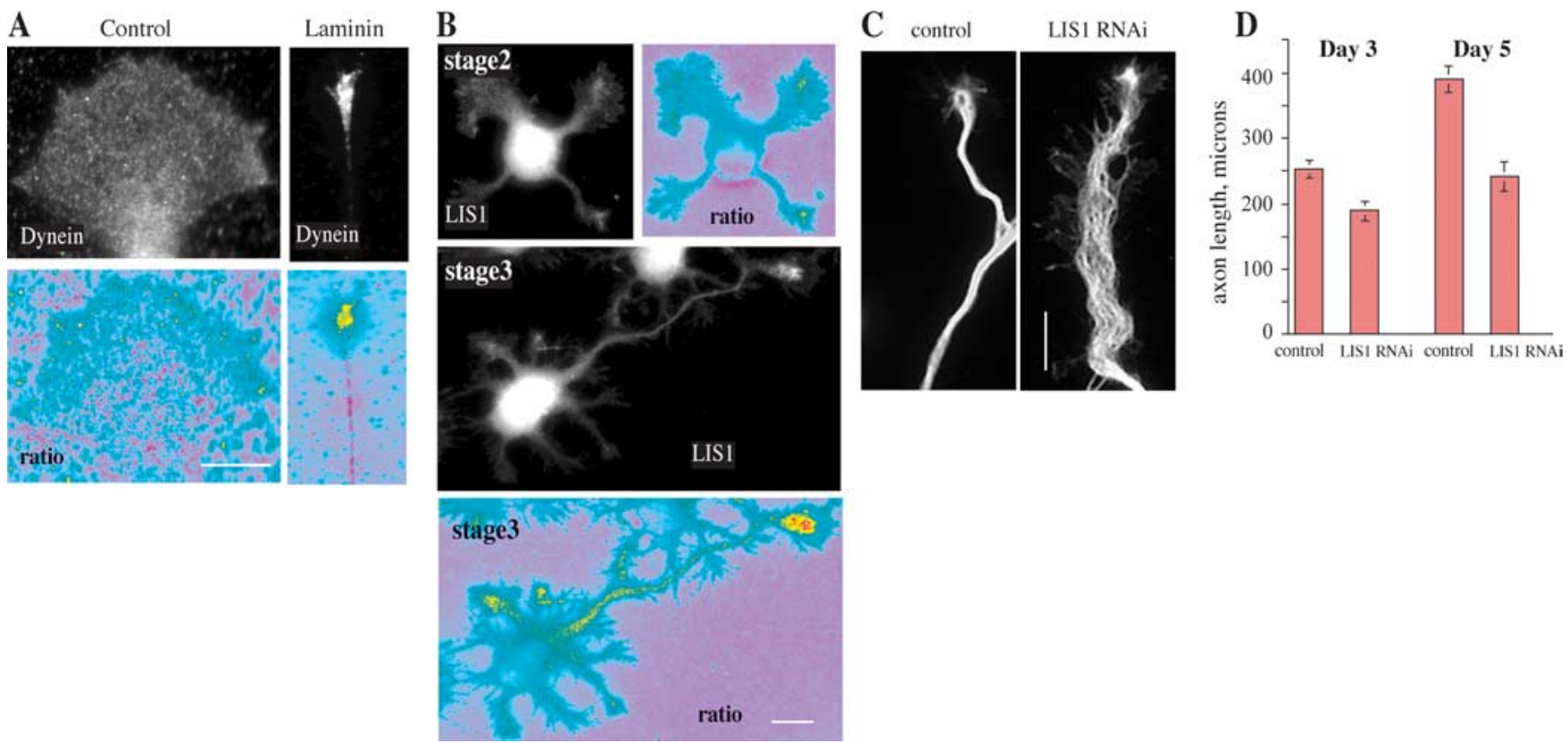

Figure 4. Localization of dynein and LIS1 proteins in axons. A, Dynein IC localization in DRG neurons. Undifferentiated neurites grown on a polyamine substrate show little concentration of dynein. Differentiated axons grown on a laminin substrate show a strong concentration of dynein in the growth cone. When each stain is ratioed against a total protein stain (DTAF), the concentration of dynein is confirmed. Scale bar, $10 \mu \mathrm{m}$. B, LIS1 localization in hippocampal axons. At differentiation stage 2 undifferentiated neurites show little concentration of LIS1. At stage 3 when an axon has formed, only the axon shows a high concentration of LIS1. This is more apparent when LIS1 is ratioed against a total protein stain. Scale bar, $10 \mu \mathrm{m}$. C, Inhibition of LIS1 by RNAi. Shown is tubulin staining of axons from hippocampal 3DIV neurons expressing scrambled control (left) or LIS1 RNAi constructs (right). Scale bar, $10 \mu \mathrm{m}$. An extended region of spread and wavy microtubules is observed in the LIS1 knock-down process. D, Average length of axons from hippocampal 3DIV and 5DIV neurons expressing these constructs. These values were significantly different [Student's unpaired two-tailed $t$ test; for $p=0.007, n=34$ control and 57 RNAi (3DIV); for $p=0.00001, n=34$ control and 20 RNAi (5DIV)]. Error bars represent the SEM.

lapse via DIC microscopy. In some experiments the neurons also were transfected with a cDNA encoding EGFP-tubulin to allow the microtubules to be visualized. Figure $6 A$ shows the normal response of a growth cone to laminin addition after growth on polyamines. The microtubules were recessed from the leading edge before the addition of laminin; afterward, however, they advanced to the leading edge and became concentrated at sites of cortical constriction. Within one-half hour thin microtubulefilled processes had grown out from these sites. In dynein antibody-injected cells the advance of microtubules was retarded, as judged both by fluorescence microscopy and by monitoring the central zone by DIC microscopy (Fig. 6B). Microtubules showed little tendency to bundle, nor were there constrictions of the adjacent plasma membrane. The actin cytoskeleton appeared to be normal as evidenced by the typical veils and filopodia seen with DIC microscopy. Strikingly, advance of the anti-dyneininjected growth cones continued at approximately the same slow neurite-like rate as before the addition of laminin, and the growth cones remained broad (Fig. 6B,C).

Inhibition of LIS1 produced similar results. The number of axons emerging from the growth cones was greatly reduced (Fig. 7). Although microtubules exhibited slow net advance, a clear P-zone persisted, and microtubules failed to coalesce into bundles at the leading edge (Fig. 7). Growth typically proceeded as before exposure to laminin, slowly and with a wide neurite. Only 1 of 10 neurons injected with LIS1 antibody displayed rapid, streamlined neuritic growth in response to laminin, compared with 8 of the 11 neurons injected with control antibody.

Small growth cones observed on a polyamine substrate typically fail to branch after laminin addition but instead narrow and shift to more rapid growth. The shaft of the nascent axon generally remains thin in these cases, even if the growth cone occasionally spreads. Microinjection of the anti-dynein IC antibody inter- fered with the shift to rapid growth (Fig. 8) as well as consolidation of the extending process. Very similar to the effect of LIS1 RNAi in the hippocampal neurons (Fig. 4C), the newly formed process was broad, with lamellipodial extensions along its length, and microtubules were spread out (Fig. $8 B$ ).

\section{Effects of dynein inhibition on EB3 behavior}

To evaluate in greater detail the effects of dynein inhibition on growth cone microtubule behavior, we electroporated chick DRG neurons with cDNA encoding a GFP-tagged version of the microtubule plus end-tracking protein EB3. EB3 associates with the growing tip of the microtubule but dissociates from its shaft to leave a comet-like track at the microtubule plus end (Stepanova et al., 2003). For these experiments laminin was added first, control or anti-dynein antibody was injected 30-60 min later, and the behavior of the EB3 comets was monitored after an additional $\sim 30 \mathrm{~min}$, well after the co-injected Alexadextran marker had permeated the growth cone.

In neurons injected with control IgG, the EB3 comets generally extended into the P-zone in relatively straight lines (Fig. $9 A, B$ ) (supplemental data 1, available at www.jneurosci.org as supplemental material). EB3 labeling persisted at the ends of most of the microtubules that were monitored, suggesting that microtubule polymerization was uninterrupted. Curiously, a substantial fraction of the advancing EB3 comets paused for periods ranging from $\sim 2$ to $30 \mathrm{~s}(7.6 \pm 1.1 \mathrm{~s}$; mean \pm SEM; $n=24$ comet tails), typically followed by additional advance. In view of the persistence of the EB3 label, this behavior is unlikely to represent changes in microtubule assembly but, rather, interference with forward microtubule extension. The proximal portion of some of the paused microtubules was faintly visible because of weak decoration with the GFP-EB3 label. Occasionally, these microtubules could be observed to bend when paused, as if com- 
A control
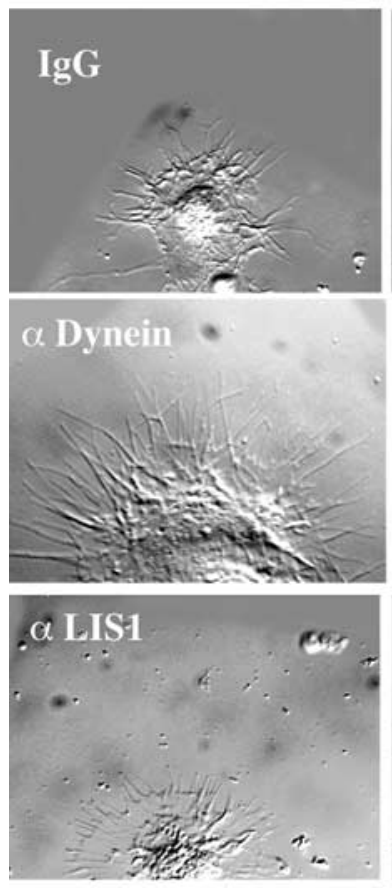

B

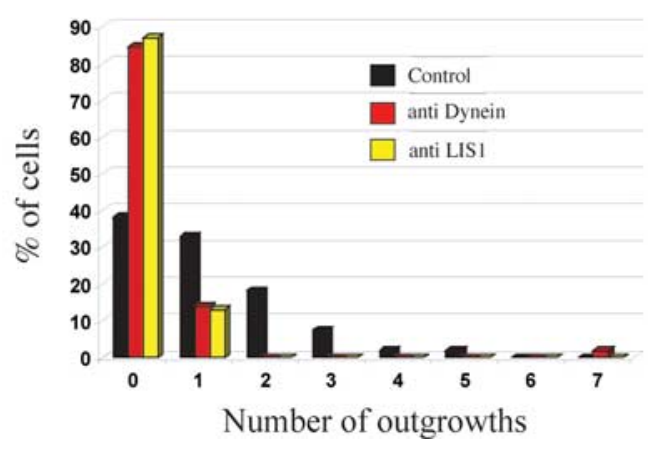

Figure 5. Effect of dynein IC and LIS1 antibody injection on growth cone morphology. A, Morphology of growth cones injected with antibody and then exposed to laminin. The growth cone of a neuron injected with control lgG shows a typical response. At 30 min after exposure to laminin two nascent axons have emerged (arrows). The growth cone of a cell injected with dynein IC antibody shows little change. After laminin treatment the growth cone has enlarged, but there are no outgrowths. The growth cone has a healthy peripheral actin network (arrow). A cell injected with polyclonal LIS1 antibody shows no outgrowths. After 30 min of exposure to laminin the growth cone has advanced a little, and lamellipodial regions are seen along the length of the newly formed neurite shaft (arrow). Scale bar, $10 \mu \mathrm{m}$. B, Quantitation of antibody injections. Chick DRG neurons were injected with monoclonal dynein IC antibody ( $(n=58)$, polyclonal LIS1 antibody $(n=31)$, or control mouse lgG $(n=55)$. Then the neurons were exposed to laminin for $30 \mathrm{~min}$ to induce neurite outgrowth. The number of laminin-induced neurites was reduced considerably in cells injected with function-blocking anti-dynein or anti-LIS1 antibody.

pressed, consistent with a physical block to their forward advance (P. Grabham and D. Goldberg, unpublished data). During periods of active extension the rates of advance for the EB3 comets were very uniform, averaging $8.7 \pm 0.5 \mu \mathrm{m} / \mathrm{min}$ (mean $\pm \mathrm{SEM}$; $n=19$ comet tails) (Fig. 9D). In a small subset of cases EB3 comets moved backward. This surprising behavior suggests rearward movement of the entire microtubule. Typically, the rearward moving EB3 comets quickly faded, suggesting that microtubule assembly had ceased. The net effect of these several behaviors, however, was penetration of the microtubules deep into the peripheral region of the growth cone (Fig. 9B), as we also had observed by tubulin immunofluorescence or live GFP-tubulin imaging (see above).

In contrast to these observations, the growth cones of neurons injected with dynein antibody were characterized by a marked reduction in the penetration of microtubule comets into the P-zone (Fig. $9 A, B$ ) (supplemental data 2, available at www.jneurosci.org as supplemental material). The number of comet tails making entries into the peripheral region decreased from $11.9 \pm 1.9$ to $4.7 \pm 0.8 / \mathrm{min}$. Those comets that advanced from the forward boundary of the central zone did so at rates similar to those for advancing comets in control cells $(7.2 \pm 0.2 \mu \mathrm{m} / \mathrm{min}$; mean \pm SEM; $n=9$ comet tails; not significantly different from control forward rates by ANOVA). The duration of microtubule extension and the frequency of pauses was reduced (Fig. 9C, bottom panel). A more striking change was in the relative number of retrogradely moving comets, which was increased greatly. The EB3 comets in these cases clearly persisted without fading as they moved retrogradely, suggesting that microtubule polymerization continued unabated as the microtubule moved rearward (Fig. 9D). The rate of retrogradely moving comet tails was $4.3 \pm 0.5 \mu \mathrm{m} / \mathrm{min}$ (mean $\pm \mathrm{SEM} ; n=$ 7 ), consistent with removal of microtubules from the peripheral region of the growth cone by retrograde actin flow (Schaefer et al., 2002). The net effect of blocking dynein was that microtubules failed to penetrate as deeply into the growth cone (Fig. 9B) as in control IgGinjected cells.

\section{Discussion}

We found that dynein, dynactin, and LIS1 all appeared at the leading edge of chick DRG growth cones during laminininduced reorganization and persisted at elevated levels in axonal growth cones in this system and in differentiating hippocampal neurons. Although dynein and its regulatory proteins were detected weakly in growth cones of slowly growing neurites, a clear and rapid enrichment was observed at sites of nascent axon outgrowth in the chick neurons, and an increase also was correlated with axonogenesis in the hippocampal neurons. That dynein and LIS1 are functionally important in growth cone remodeling was indicated by the effects of LIS1 RNAi and injection of anti-dynein and anti-LIS1 antibodies, each of which dramatically inhibited the morphological reorganization of the growth cone and interfered with microtubule behavior. These results suggest a novel role for dynein and LIS1 within the growth cone, which has important implications for understanding the growth of neuronal processes and lissencephaly. 
Dynein, dynactin, and LIS1 accumulate at sites of nascent axon outgrowth

In quiescent chick DRG growth cones the levels of dynein within the central and peripheral regions were low but detectable. The limited central region staining is somewhat surprising in view of the established role of dynein in retrograde vesicular transport. The addition of laminin to neurons caused a redistribution of dynein, LIS1, and dynactin to sites of nascent axon outgrowth. The considerably brighter staining of these proteins at these sites relative to the central zone suggests that dynein and its regulators are required at relatively high levels to effect morphogenetic changes within the growth cone. This conclusion could explain, in part, the particular sensitivity of neural progenitor cell migration to decreases in LIS1 expression (Reiner et al., 1993; Hirotsune et al., 1998; Gambello et al., 2003) and the greater sensitivity to dynein and LIS1 inhibition of centrosome reorientation and forward cell movement relative to Golgi organization (Palazzo et al., 2001; Dujardin et al., 2003). Retrograde axonal transport is inhibitable by dynein antibodies or the dominantnegative dynactin subunit dynamitin (Heerssen et al., 2004). Although defects in vesicular transport could contribute to the effects we observe in growth cones, the brief time interval between injection and analysis and the lack of effect of LIS1 inhibition on vesicular distribution we have reported (Faulkner et al., 2000; Tai et al., 2002) argue against this possibility.

Dynein enrichment at the leading edge of the growth cone was not attributable to increased total protein concentration at these sites as tested by use of DTAF as a general protein stain, nor was it attributable to increased cell thickness as tested by TIRF microscopy. The accumulation of dynein observed by using the latter method also indicated that enrichment can occur at sites associated with the underlying cell cortex. Staining was even more clearly punctate when observed by TIRF microscopy than by epifluorescence microscopy, and individual dynein spots could be observed both along and between microtubules as observed in wounded fibroblast monolayers (Dujardin et al., 2003). The nonmicrotubule-associated puncta must be associated with some other cortical element, the identity of which is unknown.

As axons began to form in response to laminin, dynein, dynactin, and LIS1 became associated more clearly with bundles of microtubules converging into the new outgrowths. Dynein, dynactin, and LIS1 subsequently remained concentrated near the tips of nascent axons as these structures elongated. The degree of

C
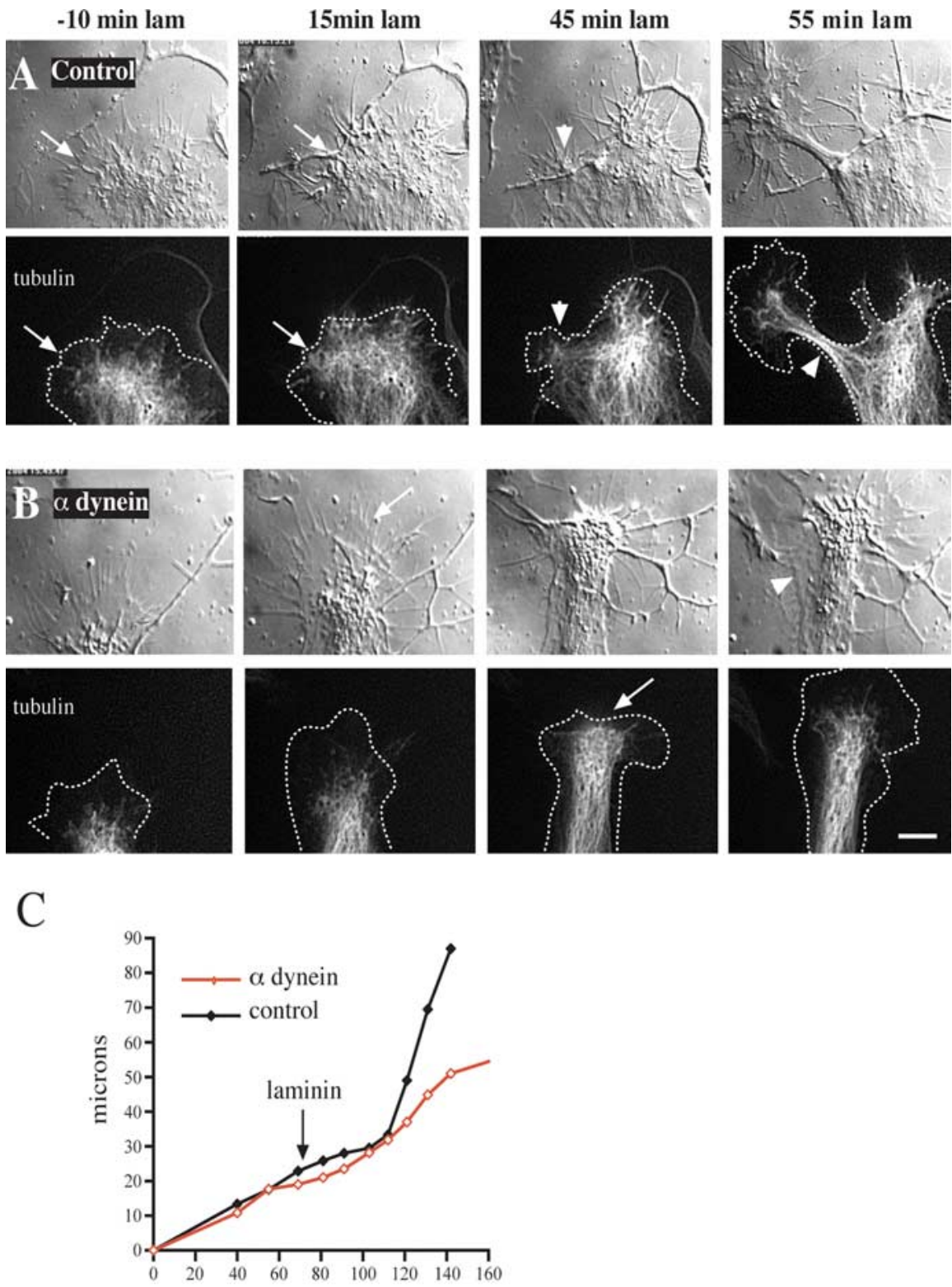

$\min$

Figure 6. Effect of anti-dynein IC injection on growth cone morphology and microtubule distribution. Chick DRG neurons grown on a polyamine substrate were transfected with cDNA encoding EGFP- $\alpha$-tubulin. Injected and uninjected control cells then were treated with laminin and monitored by DIC and fluorescence microscopy. A, Control uninjected cell. At 30 min after antibody injection and $10 \mathrm{~min}$ before laminin addition the microtubules are confined mainly to the central zone some distance from the leading edge (arrows in -10 min laminin). At $15 \mathrm{~min}$ after laminin treatment the microtubules have advanced to the leading edge (arrow). At 45 min after laminin treatment foci of microtubules have formed at the leading edge, around which the membrane also has begun to constrict (arrowhead). By 55 min a rapidly advancing neurite with a tightly constricted membrane and tightly bundled microtubules has emerged (arrowhead). B. Growth cone of a cell injected with anti-dynein IC antibody. At 30 min after antibody injection and $10 \mathrm{~min}$ before laminin treatment the growth cone displays normal spread morphology with microtubules confined to the central zone. At 15 min after laminin treatment the microtubules fail to reach the leading edge (arrow), and the growth cone advances at its initial slow rate. At $45 \mathrm{~min}$ after laminin treatment the microtubules near the leading edge but do not form foci (arrow). At 55 min after laminin treatment the peripheral zone has become reestablished. Lamellipodial protrusions also can be observed along that portion of the neurite that formed during the period of observation (arrowhead). Dotted lines in tubulin images represent the cell boundary. Scale bar, $10 \mu \mathrm{m}$. $\boldsymbol{C}$, Growth rates of the growth cones depicted in $\boldsymbol{A}$ and $\boldsymbol{B}$. The two growth cones initially advance at a comparable rate before laminin. After laminin treatment the control growth cone speeds up approximately threefold, whereas the rate of advance of the injected growth cone remains unchanged. enrichment of dynein and its regulatory proteins varied among growing processes within the same neuron. In many cases the accumulation of dynein was more pronounced in the growth cones of longer processes than in shorter ones. This result may suggest maturation of a cortical dynein-microtubule complex. 

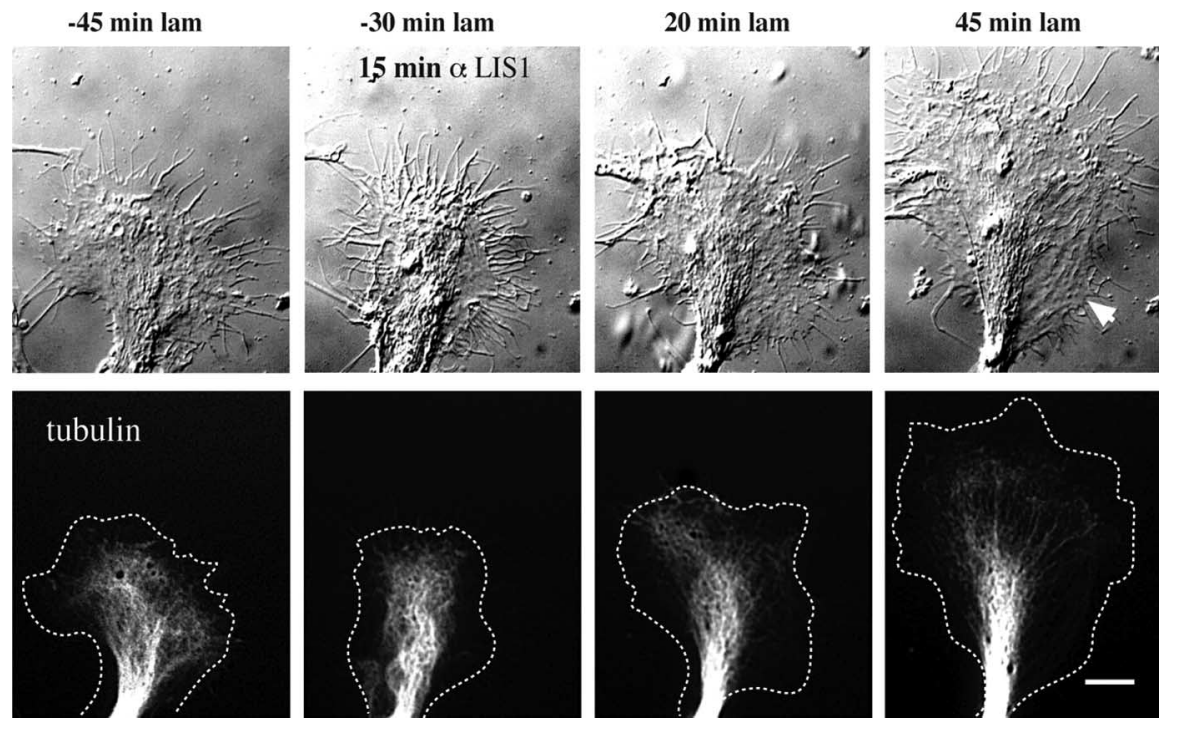

Figure 7. Effect of LIS1 antibody injection on growth cone morphology and microtubule distribution. Chick DRG neurons grown on a polyamine substrate were transfected with CDNA encoding EGFP- $\alpha$-tubulin. Expressing cells were injected with functionblocking LIS1 antibody. These cells were treated with laminin 30 min later and monitored by DIC and fluorescence microscopy. Just before antibody injection the microtubules are contained within a discrete central zone. At 20 min after laminin treatment the microtubules have reached the leading edge but fail to accumulate and form foci. The growth cone has advanced at the slow rate and retains its spread morphology. At 45 min after laminin treatment the peripheral zone has become reestablished (arrowhead). Dotted lines in tubulin images represent the cell boundary. Scale bar, $10 \mu \mathrm{m}$.

Finally, the mechanism of dynein, dynactin, and LIS1 enrichment during growth cone morphogenesis is uncertain. Whether it involves local synthesis, transport, or an increased affinity for cortical binding factors remain important issues for future investigation.

\section{Dynein and LIS1 are required physiologically for axon outgrowth}

We used a number of approaches to interfere with dynein, dynactin, and LIS1 function. Vector and oligonucleotide-based RNAi for LIS1 takes several days to reduce LIS1 levels and to produce a phenotype in rat embryos electroporated in utero with these reagents (Tsai et al., 2005). We find that RNAi using the same constructs in hippocampal neurons also takes several days to produce a phenotype. However, the rate of axonal elongation ultimately is reduced. That this effect is, at least in part, attributable to interference with growth cone function is strongly suggested by the dramatic effects we observed on hippocampal growth cone organization (Fig. 4).

In contrast to the hippocampal neurons, the chick DRG neurons provide an excellent system by which to test for more immediate effects on growth cone behavior and to monitor the initial stages of axonogenesis. RNAi and dominant negatives are less well suited to this system. Instead, antibody injection was used in this study to interfere with dynein and LIS1 in a temporally controlled manner. The effects of the antibodies were surprisingly dramatic, indicating that dynein and LIS1 play very significant roles in growth cone remodeling and axon formation. The similarity in phenotypic effects produced by antibodies against two distinct components of the dynein pathway provides very strong support for the specificity of the effects. Both antibodies produced striking reductions in the number of de novo laminin-induced processes, and growth continued at the slower rates characteristic of undifferentiated neurites seen on polyamines, suggesting underlying mechanistic differences in the

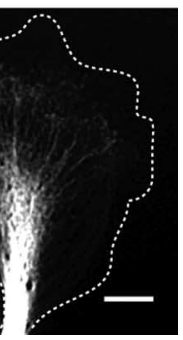

slow and rapid types of growth. Interference with dynein and LIS1 each produced changes in the behavior and organization of microtubules. It has been reported, however, that filamentous actin is reduced in the leading process of isolated neurons from $\mathrm{LIS}^{+/-}$mice as assayed by immunofluorescence microscopy (Kholmanskikh et al., 2003). In that study RhoA activity was found to be increased, whereas Rac1 and Cdc42 activity were decreased, possibly accounting for the observed effects on the actin cytoskeleton. We note that the leading process in that study is presumed to represent a migratory process rather than an axon. Our data did not reveal obvious effects on actin-based structures such as filopodia and veils. We do note that Rac1 concentrates at sites of neurite outgrowth during the laminin response, and outgrowth depends on Rac activity (Grabham et al., 2003).

\section{Role of dynein and LIS1 in microtubule-} mediated growth cone remodeling

Together, our results suggest that cytoplasmic dynein, regulated by dynactin and LIS1, is involved in regulating the organization of microtubules within the growth cone. In laminintreated DRG neurons dynein and LIS1 inhibition had the pronounced effect of limiting the extent to which microtubules penetrated the P-zone. Live imaging of EB3 behavior allowed for greatly increased resolution of individual microtubules and strongly confirmed this observation. In addition, the detailed kinetic behavior of the EB3 comets provided important insight into the relative roles of microtubule assembly and movement.

In Aplysia growth cones most microtubule extension into the $\mathrm{P}$-zone results from polymerization rather than translocation (Kabir et al., 2001; Schaefer et al., 2002). We found that EB3 comets in growth cones of chick DRG neurons moved forward at a uniform rate, similar to rates previously reported for microtubule assembly in other neurons (Schaefer et al., 2002; Stepanova et al., 2003). These observations strongly suggest that most of the microtubule advance we observed in the laminin-treated chick DRG growth cones resulted from microtubule assembly rather than translocation. Our evidence for increased localization of dynein, dynactin, and LIS1 in growth cones and, specifically, within the P-zone during axonogenesis (Figs. 1-3) indicates that the motor protein is available to interact with microtubules extending into this region. We found, in fact, that microtubule excursions into the peripheral region of the growth cone were curtailed dramatically when dynein was inhibited. Many EB3 comet tails made extended backward movements when dynein was inhibited, something infrequently observed in the control cells. Because the EB3 comet tails persisted during rearward microtubule movement, the withdrawal of these microtubules could not be attributed to depolymerization. Instead, the rates of rearward movement are consistent with the effects of retrograde actin flow. Thus we conclude that the recruitment of dynein in response to laminin allows microtubules to resist retrograde actin flow and advance into the peripheral region of the growth cone, thus permitting rapid axonal growth (Fig. 10). A role for dynein in resisting forces generated by actin also has been suggested for 
axons and migrating fibroblasts (Ahmad et al., 2000; Gomes et al., 2005), but a direct demonstration of this mechanism at the single microtubule level and its identification as an important feature in growth cone behavior have not been reported previously.

Another feature of microtubule behavior affected by anti-dynein antibody injection is the tendency of microtubules to pause, especially during extension (Fig. 9). Whether these pauses represent stalled microtubules that continue to assemble (Fig. 9D) or an effect of dynein inhibition on the activity of microtubule tipassociated proteins remain intriguing questions for future investigation. We also note that mutations in dynein or LIS1 in lower eukaryotes have been reported to lead to longer microtubules (Carminati and Stearns, 1997; Han et al., 2001), an effect that, in Aspergillus, was attributed to a decrease in microtubule depolymerization rate. Whether dynein, therefore, affects microtubule dynamics differently in vertebrate and lower eukaryotic systems and whether this difference relates to an interaction of dynein with the sides or tip of the microtubule remain to be explored.

We observed dynein and LIS1 to persist at the tip of rapidly growing axons after laminin treatment. Many of these processes still have discernible, albeit smaller, growth cones in which the dynein still could be seen. However, dynein also was clearly located at the tip of even the finest processes in which growth cone organization was not discerned readily. The specific function of dynein at this stage is uncertain. We suspect that, in these finer processes, dynein continues to exert tension on microtubules to facilitate additional growth of the axon. The levels of dynein and LIS1 in nascent processes vary. Conceivably, processes that recruit dynein and LIS1 more effectively are those that will predominate, e.g., in polarizing hippocampal neurons, a possibility that remains to be explored fully.

Another effect of dynein or LIS1 inhibition was a decrease in coalescence of microtubules. This effect was not observed throughout the neuronal process but, rather, in the portion of the DRG neurons formed after dynein inhibition (Fig. 8). Associated with this effect was a widening of the process and the appearance of ectopic, lateral lamellipodia. The mechanism underlying these effects is uncertain, but they suggest some ability of dynein, assisted by LIS1, to draw microtubules together. This could be a direct effect if cytoplasmic dynein, like axonemal dynein, functions in some circumstances to induce sliding between microtubules. Alternatively, cooperative forces of cortically bound dynein on

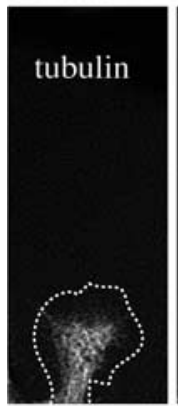
unchanged.

\section{A Control}
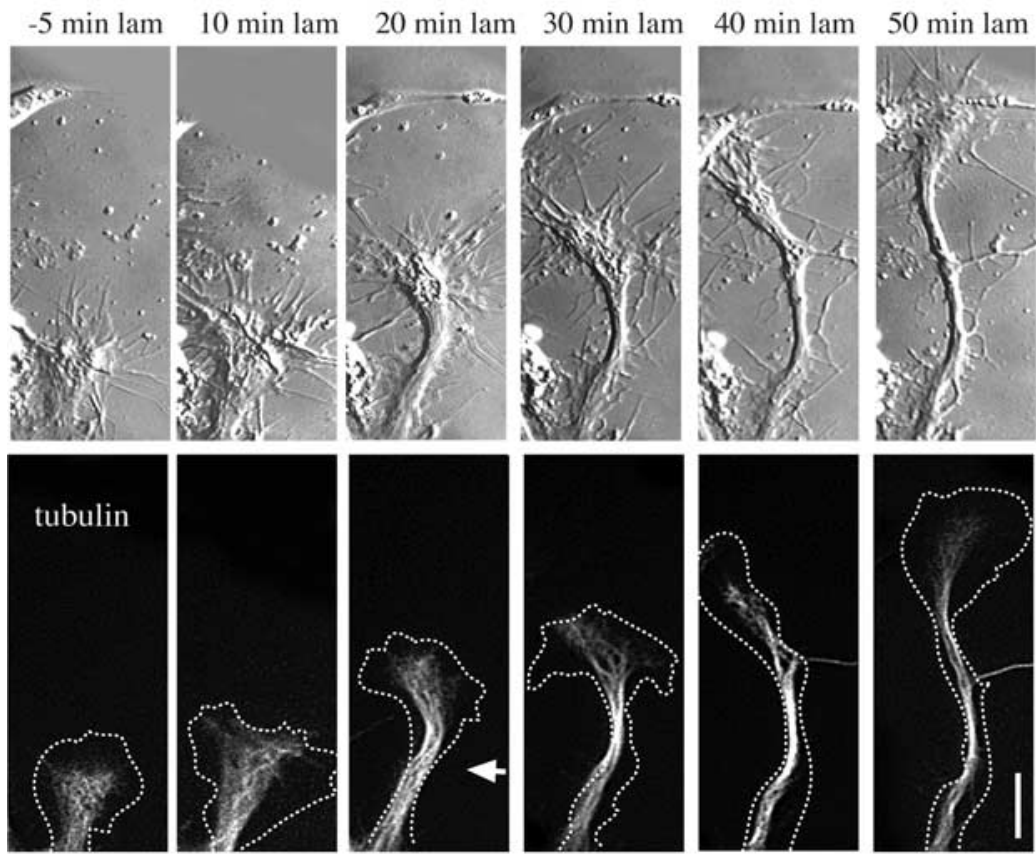

\section{$\mathrm{B}$ antibody injected}

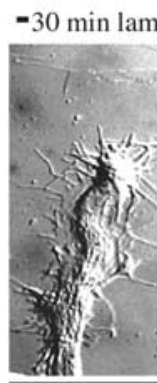

tubulin
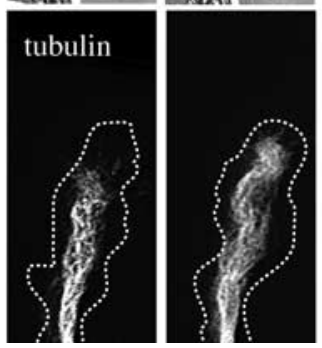
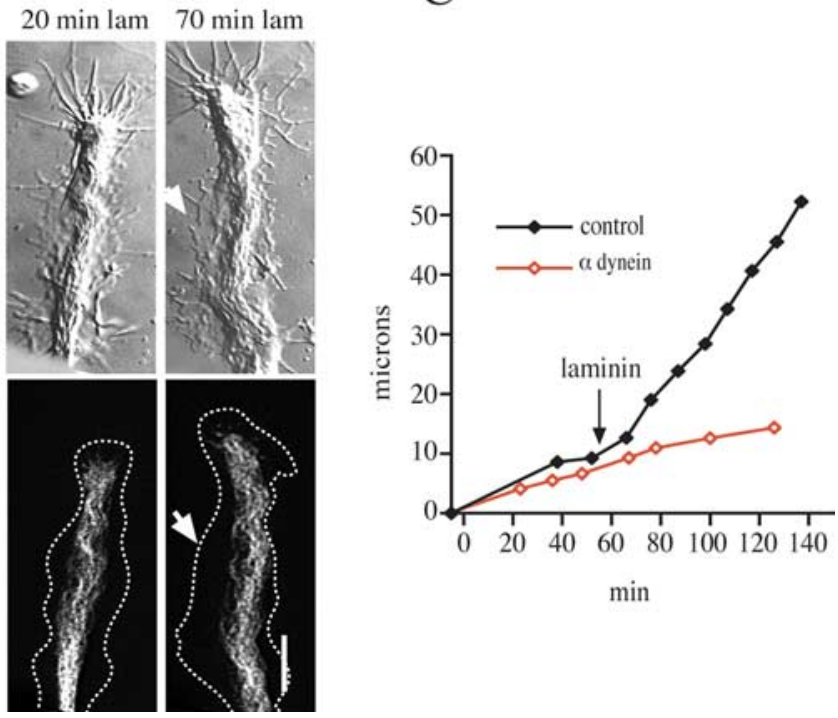

Figure 8. Effect of dynein antibody injection on neurites with small growth cones. Chick DRG neurons were treated as described in the legend to Figure 4. A, Small growth cone of a control cell. By 20 min after laminin treatment the growth cone is narrower, and the neck is constricted (arrowhead). Constriction of the membrane and microtubules proceeds in subsequent frames as the growth cone advances more rapidly. Dotted lines in tubulin images represent the cell boundary. $\boldsymbol{B}$, A small growth cone of a cell injected with dynein antibody. At 20 min after laminin treatment the growth cone continues to advance, but there is no constriction of the membrane or microtubules. The growth cone remains at the same width. In contrast to the control cell, lamellipodia remain well spread along the sides of the newly formed process (arrowhead at $70 \mathrm{~min}$ ). Scale bar, $10 \mu \mathrm{m}$. C, Growth rates of the growth cones depicted in $\boldsymbol{A}$ and $\boldsymbol{B}$. The two growth cones initially advance at a comparable rate before laminin. After laminin treatment the control growth cone speeds up approximately threefold, whereas the rate of advance of the injected growth cone remains multiple microtubules could serve to compact the entire neuronal process (Fig. 10). The effect of dynein and LIS1 inhibition on only the newly formed regions of the axon suggests that, once consolidated, the roles of these proteins are different. This possibility is supported by the results of LIS1 RNAi in developing rat brain (Tsai et al., 2005) in which the extension of axon-like pro- 


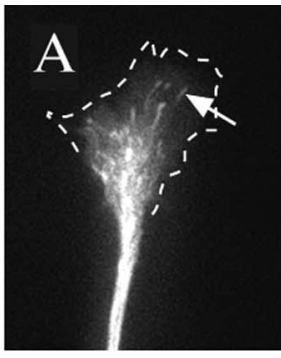

control IgG

B

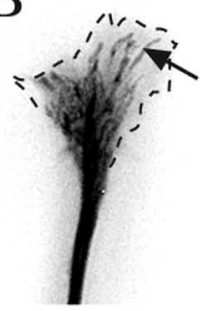

control IgG

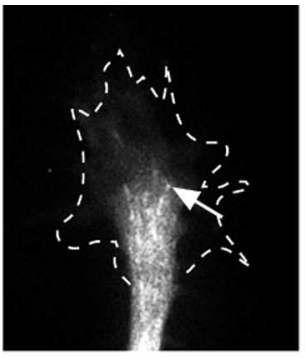

$\alpha 74.1$

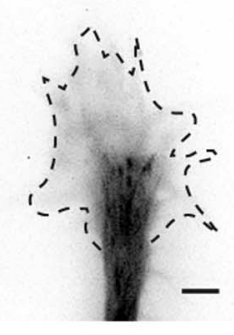

$\alpha 74.1$
$\mathrm{C}$

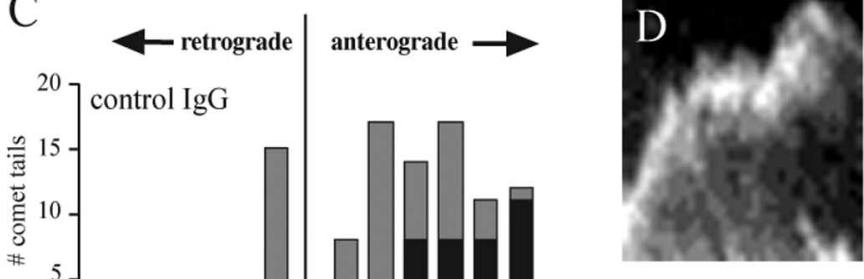

control IgG

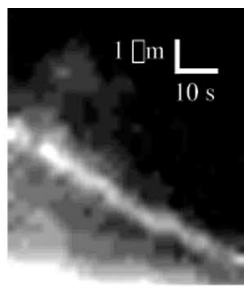

$\alpha 74.1$

Figure 9. Effect of dynein inhibition on microtubule dynamics. $A$, Appearance of EB3 comet tails (arrows) at a single time point in the growth cones of control lgG and anti-dynein-injected ( $\alpha 74.1)$ chick DRG neurons. Dotted lines indicate growth cone boundary. $\boldsymbol{B}$, History maps of comet tail activity under each condition. All frames from a 1 min video sequence (supplemental data 1,2 , available at www.jneurosci.org as supplemental material) were superimposed to visualize the comet tail pathways. Arrow shows a comet tail in control conditions penetrating deep into the peripheral region. Scale bar, $10 \mu \mathrm{m}$. C, Analysis of comet tail movements from eight growth cones in each condition. Histograms of the duration of anterograde and retrograde movements of comet tails show dramatic inhibition of anterograde extension in cells injected with dynein function-blocking antibody. Histogram showing numbers of comets exhibiting pauses is superimposed. $\boldsymbol{D}$, Kymographs of comet tail advance in control cells and rearward movement in anti-dynein-injected cells. A narrow rectangle covering the path of comet tails for 35 frames ( 2 sapart) was used to create kymographs of each movement. Forward movement associated with the control microtubule at left is rapid at microtubule assembly rates but is marked by a pause, with persistent rapid oscillations during this period. Rearward movement in dynein-inhibited cells shows a slow steady trajectory at rates consistent with retrograde actin flow.

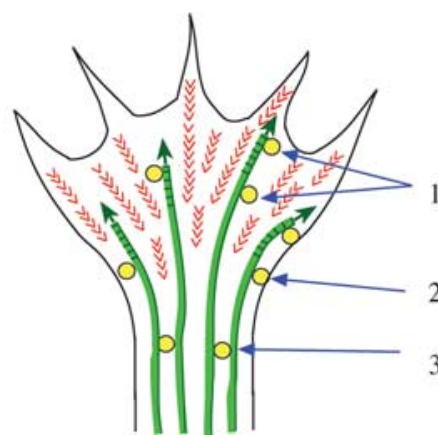

B

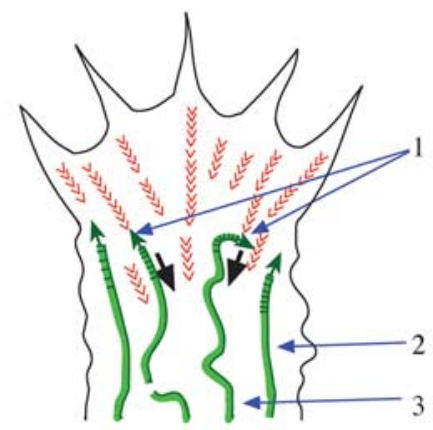

Figure 10. Diagrammatic representation of potential dynein functions in axonal growth cones. $A$, Data from this study indicate that in a rapidly growing axonal growth cone dynein accumulates at the cell cortex and interacts with assembling microtubules to allow them to resist retrograde actin flow (red arrowheads) and penetrate into the peripheral region (1). Dynein also mediates constriction of the membrane at the growth cone neck (2). Direct or indirect dynein-dependent interactions between microtubules facilitate their bundling within the consolidated axon (3). B, Effects of dynein and LIS1 inhibition. Microtubules are pushed backward (black arrows) by retrograde actin flow, despite continuing to polymerize (1). The cell cortex at the growth cone neck fails to constrict, and lamellipodia extend laterally behind the growth cone (2). Microtubules appear splayed in the region behind the growth cone, although not in an axon formed before the inhibition of LIS1 or dynein (3).

cesses is blocked as LIS1 levels are reduced, without apparent loss of the previously formed process. A related effect has been observed in the current study in hippocampal neurons, in which LIS1 RNAi resulted in broadening of the distal portion of the axon with associated lamellipodia. This region is likely to have formed once LIS1 levels had become reduced. Again, no obvious effects on the more proximal regions of the axon were observed.

The current results imply a role for dynein and LIS1 in neuronal differentiation and pathfinding in vivo. Defects in neuronal development resulting from mutations in dynein and dynactin subunits have been reported (Phillis et al., 1996; Allen et al., 1999). In the case of LIS1, RNAi in rat brain neural progenitor cells revealed limited effects on the migratory process of bipolar cells (Tsai et al., 2005), but elongation of axon-like processes extending from these cells was arrested. Although the identity of these processes remains to be established fully and growth cones per se have not been identified, these results provide potential support for the current in vitro findings.

\section{Conclusion}

Together, our results identify a new subcellular site at which LIS1, dynein, and dynactin function together within neurons. The role of these proteins within the growth cone and in developing processes promises to be of considerable significance in understanding neuronal pathfinding, morphogenesis, and migration.

\section{References}

Ahmad FJ, Hughey J, Wittmann T, Hyman A, Greaser M, Baas PW (2000) Motor proteins regulate force interactions between microtubules and microfilaments in the axon. Nat Cell Biol 2:276-280.

Allen MJ, Shan X, Caruccio P, Froggett SJ, Moffat KG, Murphey RK (1999) Targeted expression of truncated Glued disrupts giant fiber synapse formation in Drosophila. J Neurosci 19:9374-9384.

Burakov A, Nadezhdina E, Slepchenko B, Rodionov V (2003) Centrosome positioning in interphase cells. J Cell Biol 162:963-969.

Carminati JL, Stearns T (1997) Microtubules orient the mitotic spindle in 
yeast through dynein-dependent interactions with the cell cortex. J Cell Biol 138:629-641.

Chamak B, Prochiantz A (1989) Influence of extracellular matrix proteins on the expression of neuronal polarity. Development 106:483-491.

Dujardin DL, Barnhart LE, Stehman SA, Gomes ER, Gundersen GG, Vallee RB (2003) A role for cytoplasmic dynein and LIS1 in directed cell movement. J Cell Biol 163:1205-1211.

Echeverri CJ, Paschal BM, Vaughan KT, Vallee RB (1996) Molecular characterization of the $50-\mathrm{kD}$ subunit of dynactin reveals function for the complex in chromosome alignment and spindle organization during mitosis. J Cell Biol 132:617-633.

Esch T, Lemmon V, Banker G (1999) Local presentation of substrate molecules directs axon specification by cultured hippocampal neurons. J Neurosci 19:6417-6426.

Etienne-Manneville S, Hall A (2001) Integrin-mediated activation of Cdc42 controls cell polarity in migrating astrocytes through PKC $\zeta$. Cell 106:489-498.

Faulkner NE, Dujardin DL, Tai CY, Vaughan KT, O'Connell CB, Wang Y, Vallee RB (2000) A role for the lissencephaly gene LIS1 in mitosis and cytoplasmic dynein function. Nat Cell Biol 2:784-791.

Gambello MJ, Darling DL, Yingling J, Tanaka T, Gleeson JG, Wynshaw-Boris A (2003) Multiple dose-dependent effects of Lis1 on cerebral cortical development. J Neurosci 23:1719-1729.

Gomes ER, Jani S, Gundersen GG (2005) Nuclear movement regulated by Cdc42, MRCK, myosin, and actin flow establishes MTOC polarization in migrating cells. Cell 121:451-463.

Grabham PW, Reznik B, Goldberg DJ (2003) Microtubule and Rac1dependent F-actin in growth cones. J Cell Sci 116:3739-3748.

Han G, Liu B, Zhang J, Zuo W, Morris NR, Xiang X (2001) The Aspergillus cytoplasmic dynein heavy chain and NUDF localize to microtubule ends and affect microtubule dynamics. Curr Biol 11:719-724.

Hattori M, Adachi H, Tsujimoto M, Arai H, Inoue K (1994) Miller-Dieker lissencephaly gene encodes a subunit of brain platelet-activating factor. Nature 370:216-218.

Heerssen HM, Pazyra MF, Segal RA (2004) Dynein motors transport activated Trks to promote survival of target-dependent neurons. Nat Neurosci 7:596-604.

Hirotsune S, Fleck MW, Gambello MJ, Bix GJ, Chen A, Clark GD, Ledbetter DH, McBain CJ, Wynshaw-Boris A (1998) Graded reduction of Pafah1b1 (Lis1) activity results in neuronal migration defects and early embryonic lethality. Nat Genet 19:333-339.

Kabir N, Schaefer AW, Nakhost A, Sossin WS, Forscher P (2001) Protein kinase $\mathrm{C}$ activation promotes microtubule advance in neuronal growth cones by increasing average microtubule growth lifetimes. J Cell Biol 152:1033-1044.

Kholmanskikh SS, Dobrin JS, Wynshaw-Boris A, Letourneau PC, Ross ME (2003) Disregulated RhoGTPases and actin cytoskeleton contribute to the migration defect in Lis1-deficient neurons. J Neurosci 23:8673-8681.

Kim MH, Cooper DR, Oleksy A, Devedjiev Y, Derewenda U, Reiner O, Otlewski J, Derewenda ZS (2004) The structure of the N-terminal domain of the product of the lissencephaly gene Lis1 and its functional implications. Structure 12:987-998.

Koizumi H, Yamaguchi N, Hattori M, Ishikawa TO, Aoki J, Taketo MM, Inoue K, Arai H (2003) Targeted disruption of intracellular type I platelet-activating factor acetylhydrolase catalytic subunits causes severe impairment in spermatogenesis. J Biol Chem 278:12489-12494.

Lein PJ, Higgins D (1989) Laminin and a basement membrane extract have different effects on axonal and dendritic outgrowth from embryonic rat sympathetic neurons in vitro. Dev Biol 136:330-345.

Lein PJ, Banker GA, Higgins D (1992) Laminin selectively enhances axonal growth and accelerates the development of polarity by hippocampal neurons in culture. Brain Res Dev Brain Res 69:191-197.
Lewis AK, Bridgman PC (1996) Mammalian myosin I $\alpha$ is concentrated near the plasma membrane in nerve growth cones. Cell Motil Cytoskeleton 33:130-150.

Palazzo AF, Joseph HL, Chen YJ, Dujardin DL, Alberts AS, Pfister KK, Vallee RB, Gundersen GG (2001) Cdc42, dynein, and dynactin regulate MTOC reorientation independent of Rho-regulated microtubule stabilization. Curr Biol 11:1536-1541.

Phillis R, Statton D, Caruccio P, Murphey RK (1996) Mutations in the $8 \mathrm{kDa}$ dynein light chain gene disrupt sensory axon projections in the Drosophila imaginal CNS. Development 122:2955-2963.

Reiner O, Carrozzo R, Shen Y, Wehnert M, Faustinella F, Dobyns WB, Caskey CT, Ledbetter DH (1993) Isolation of a Miller-Dieker lissencephaly gene containing G-protein $\beta$-subunit-like repeats. Nature 364:717-721.

Rivas RJ, Burmeister DW, Goldberg DJ (1992) Rapid effects of laminin on the growth cone. Neuron 8:107-115.

Sasaki S, Shionoya A, Ishida M, Gambello MJ, Yingling J, Wynshaw-Boris A, Hirotsune S (2000) A LIS1/NUDEL/cytoplasmic dynein heavy chain complex in the developing and adult nervous system. Neuron 28:681-696.

Schaefer AW, Kabir N, Forscher P (2002) Filopodia and actin arcs guide the assembly and transport of two populations of microtubules with unique dynamic parameters in neuronal growth cones. J Cell Biol 158:139-152.

Smith DS, Niethammer M, Ayala R, Zhou Y, Gambello MJ, Wynshaw-Boris A, Tsai LH (2000) Regulation of cytoplasmic dynein behaviour and microtubule organization by mammalian Lis1. Nat Cell Biol 2:767-775.

Steffen W, Karki S, Vaughan KT, Vallee RB, Holzbaur ELF, Weiss DG, Kuznetsov SA (1997) The involvement of the intermediate chain of cytoplasmic dynein in binding the motor complex to membranous organelles of Xenopus oocytes. Mol Biol Cell 8:2077-2088.

Stepanova T, Slemmer J, Hoogenraad CC, Lansbergen G, Dortland B, De Zeeuw CI, Grosveld F, van Cappellen G, Akhmanova A, Galjart N (2003) Visualization of microtubule growth in cultured neurons via the use of EB3-GFP (end-binding protein 3-green fluorescent protein). J Neurosci 23:2655-2664.

Susalka SJ, Nikulina K, Salata MW, Vaughan PS, King SM, Vaughan KT, Pfister KK (2002) The roadblock light chain binds a novel region of the cytoplasmic dynein intermediate chain. J Biol Chem 277:32939-32946.

Tai CY, Dujardin DL, Faulkner NE, Vallee RB (2002) Role of dynein, dynactin, and CLIP-170 interactions in LIS1 kinetochore function. J Cell Biol 156:959-968.

Tanaka T, Serneo FF, Higgins C, Gambello MJ, Wynshaw-Boris A, Gleeson JG (2004) Lis1 and doublecortin function with dynein to mediate coupling of the nucleus to the centrosome in neuronal migration. J Cell Biol 165:709-721.

Tang D, Goldberg DJ (2000) Bundling of microtubules in the growth cone induced by laminin. Mol Cell Neurosci 15:303-313.

Tarricone C, Perrina F, Monzani S, Massimiliano L, Kim MH, Derewenda ZS, Knapp S, Tsai LH, Musacchio A (2004) Coupling PAF signaling to dynein regulation: structure of LIS1 in complex with PAF-acetylhydrolase. Neuron 44:809-821.

Tsai J-W, Chen Y, Kriegstein AR, Vallee RB (2005) LIS1 RNA interference blocks neural stem cell division, morphogenesis, and motility at multiple stages. J Cell Biol 170:935-945.

Vaughan KT, Hughes SH, Echeverri CJ, Faulkner NF, Vallee RB (1999) Colocalization of dynactin and cytoplasmic dynein with CLIP-170 at microtubule distal ends. J Cell Sci 112:1437-1447.

Xiang X, Fischer R (2004) Nuclear migration and positioning in filamentous fungi. Fungal Genet Biol 41:411-419.

Yan W, Assadi AH, Wynshaw-Boris A, Eichele G, Matzuk MM, Clark GD (2003) Previously uncharacterized roles of platelet-activating factor acetylhydrolase $1 \mathrm{~b}$ complex in mouse spermatogenesis. Proc Natl Acad Sci USA 100:7189-7194. 